\title{
A STUDY OF THE TEACHERS' ROLES IN THE IMPLEMENTATION OF SCIENTIFIC APPROACH IN TEACHING ENGLISH AT SMP NEGERI 1 SINGARAJA
}

\author{
Ayustina, K.P.P. \\ English Language Education, Ganesha University of Education, Singaraja \\ Email: paramitha.ayustina@yahoo.com \\ Batan, I.G. \\ English Language Education, Ganesha University of Education, Singaraja \\ Email: igedebatan@gmail.com \\ Mahayanti, N.W.S. \\ English Language Education, Ganesha University of Education, Singaraja \\ Email: mahayantisurya@yahoo.co.id
}

\begin{abstract}
The implementation of Curriculum 2013 indicated that there is a switch of the teachers' role in the process of teaching and learning from resource becoming facilitator. This study aimed to find out the roles that the teachers play in the classrooms when teaching English at SMP Negeri 1 Singaraja and to know responses of the students toward it. It followed qualitative interactive descriptive model, approach, and design which was adopting the framework of Maxwell (2012). It involved 3 teachers and 174 students. The required data for this study were collected through observation and distributing questionnaire. Since the data were analyzed descriptively, it was adopted the framework developed by Miles and Huberman (1994). The results of data analysis show that there are five roles the teachers played in the classroom when teaching English at SMP Negeri 1 Singaraja such as prompter or motivator, facilitator, controller, organizer, and assessor and the responses of the students toward it mostly dominated by positive attitude. In short, most of the roles that the teachers played support the student-centered learning. It is the result of the classroom focused activities developing on giving exercises, completing task, and doing practice of language used.
\end{abstract}

Keywords: assessor, controller, facilitator, organizer, prompter, scientific approach

\section{INTRODUCTION}

In Indonesia, curriculum and learning process are two things that cannot be separated. The development of education system in Indonesia is based on its curriculum. A curriculum is developed to get students' qualified outcomes. Hubball and Burt (2004 cited in Rumahlatua, Huliselana, and Takariaa, 2016), stated that the reformation of curriculum is a complex, diverse, and repetitious process which changes ideas into policies, transforms into behavior, and expresses as social actions. There are several curriculum that had ever been implemented in Indonesia: 1967, 1974, 1984, 1994, Competence-Based Curriculum, School-Based Curriculum, and the latest curriculum is Curriculum 2013 (Firmansyah, 2015).

In the implementation of Curriculum 2013, the word "teaching" switched to the word "learning how to learn" (Ministry of Education and Culture in Indonesia, 2014). If in the previous curriculum, School-Based Curriculum, the teachers became the center of learning, here, it forces the students to be involved as the center in the process of learning. This point is proved by one of principles written in the Regulation of Ministry of Education and Culture in Indonesia no. 22 (2012). It can be found that the first principle has been written as "From the students are told to the students to find out". It clearly refers to the implementation of Student-Centered Learning where the students are the center of the study. 
According to Guzman (2016), student-centered learning (SCL) is an instructional approach in which students influence the content, activities, materials, and pace of learning. It is a method in which the student is in the center of the learning and the teacher has at least impression in language instruction (Zohrabi, Torabil, and Baybourdiani, 2012). Thanh (2010) stated that this happened because it believes that a student-centered learning approach is aimed to provide the students with new skills required by the labor market like independence, creativeness, activeness and cooperativeness. Student-centered involves providing opportunities for students to meaningfully talk and listen, write, read, and reflect on the content, ideas, issues, and concerns of an academic subject. By looking the definitions, it can be seen as an "active learning" which helps students to learn independently.Moreover, in the implementation of Student-Centered Learning, based on the Regulation of Ministry of Education and Culture in Indonesia no. 22 (2012), it must be implemented together with Scientific Approach since this approach will have the students who need to be able to engage directly in the process of acquiring knowledge. Related to this, the roles of teachers must also be different. There is an implication on the teachers' roles, especially in teaching EFL for this context.

According to Harmer (2007), there are the descriptions for 8 roles of teacher that can be played in the process of teaching such as teacher as facilitator, teacher as resource, teacher as controller, teacher as prompter or motivator, teacher as participant, teacher as tutor, teacher as organizer, and teacher as assessor.First role of teachers is as facilitator. According to Archana and Kumbakhonam (2016), as a facilitator for their students, the teachers have to direct and support students in learning for themselves as a self-explorer. They should develop best learning environment which reflects the students' life in societal, intellectual, and linguistic occurrences. As a facilitator, teachers need to have a strong foundation of themselves in relation to their personal growth. According to Harmer (2007), this role is the main role among all roles. Supported Harmer's Theory (2007), Osman (2015) stated that teacher as facilitator need to assist a group of people in grasping at their common targets and in achieving them without any intervention on his/her behalf. He added that the teachers need to give learners some space to let the spirits of creativity and innovation. In this case, teachers need to facilitate the students by providing the activities or things which students can discuss on. They also need to support the learning process by helping the students to do the work when they find difficulties.

The second role of teachers is as resource. According to Wilder (2017), the teacher is a kind of walking content resource for the students when they need help to solve their problems in learning. When they instruct, they appear as the center of the learning process imparting all knowledge to a passive participant. They control what is taught and when. It is up to the participant to adapt their personal style and prior knowledge to learn new skills and knowledge.

The third role is teacher as controller. According to Bălcescu (2015), teacher as controller means that the teacher is in complete charge of the class in order to control what students do, what they say and how they say it. It supported by Harmer's Theory (2007). He stated that when teachers act as controllers, they are in charge of the class and of the activity taking place. Teachers are often leading the activity from the front of the class even there are also times when acting as controllers for group of students when there is group discussion activity in the classroom. For example, the teachers can be controllers when giving explanations, organizing questions, and answer work, a little bit lecturing when the students need help, and making announcements that need to be followed or done by the students (Harmer, 2007).

Next, the fourth role is teachers as prompter or motivator. Still according to Bălcescu (2015), the role that should be played by the teachers is the teacher encourages students to participate in the learning process by making suggestions on how to proceed in an activity. According to Harmer (2007), when the students lose the thread of what is going on, or they are "lost for words", the teachers need to be able to nudge them forward in discreet and supportive way. In such situations, teachers need to offer words or phrases as the clues for the students, suggest them to say something or in the other words, or suggest them what could come next after their last word.

Moreover, as teacher, it is needed to prompt or motivate the students to speak English rather than use their Mother Tongue (Harmer, 2007). The teacher also needs to encourage their students to enjoy the lesson (Harmer, 2007). The following role is as the participant. This role is well-known by the people. The teachers need to play this role in order to participate in the learning process. According to Harmer (2007), the traditional picture of teachers is they are standing back from the 
activity, letting the students get on with it, and only interrupting them sometimes to correct mistakes. However, it must be changed presently. It is a good time when the teachers join in an activity not only as the teachers, but also as participant in their own right (Harmer, 2007). For instance, when the teachers take part in a discussion. The teachers may liven things up from the inside instead of always having to prompt or organize from outside of the group (Harmer, 2007). The students might enjoy it, but the danger is that the teachers unintentionally will dominate the proceedings since they have more knowledge than the students.

Next, for the teachers as tutor, it is about when the teachers work with individuals or small groups who are working on longer projects. They need to make the students clear about the lesson by telling them what they do not really understand on (Harmer, 2007). It is a bit similar with the role of teachers as resource, but then it is combined with the other role of teacher, that is as prompter. However, it is difficult to be tutors in a very large group since the term implies a deeper relationship than that of a controller or organizer (Harmer, 2007). As good tutors, teachers need to make sure that every student gets the same chance to listen on teachers' explanations individually until there is no doubt left (Harmer, 2007). On the other hand, as the good teachers, they need to be able to organize their students and activities in the classroom.

According to Harmer (2007), as the organizer, the teachers often involve giving the students information, telling them how they are going to do the activity, putting them into pairs or groups and finally closing things down when it is time to stop. The teachers will often say something like, "Now, we are going to do this because..." and will also tell rationale for the activity students are asked to do (Harmer, 2007). Once the students are ready, it is important for the teachers to give instructions on what students should do first, next, and so on. It avoids the confusing things happened in the classroom (Harmer, 2007). In addition, the teachers also need to be the reminder for the students, for instance, in case of time. Telling the students when to start or stop working is needed to be done by the teachers (Harmer, 2007).

And the last teachers' role is as assessor. It is well-known that an assessor is the one who has a duty to grade the students and correct learners' mistakes by giving them feedback in various ways. According to Harmer (2007), what students expect from their teachers are feedback and correction since the students should know what they are looking for and what success looks like so they can measure themselves later. Teachers also need to grade students in various ways and indicate whether or not students are getting their English right (Harmer, 2007). So, the teachers' roles above are closely related to the process of classroom instruction based on the scientific approach and Curriculum 2013 has recommended the roles of the teachers that needed to be played in the implementation of Scientific Approach.

Based on Regulation of the Ministry of Education and Culture in Indonesia No. 81a (2013), it has set the teachers' roles that needed to be played in each stage of Scientific Approach. Firstly, in the observing stage, the teachers at least play their roles as the facilitator in the observing stage. Second, in the questioning stage, teachers need to encourage and motivate the students by playing their role as prompter or motivator. Exploring and associating are the follow up of the questioning stage. It is time to gather information from various sources through various means (Regulation of the Ministry of Education and Culture of the Republic of Indonesia No. 81a, 2013). Therefore, the role of teachers that should be played in the exploring and associating stages are at least as facilitator, organizer, and controller. And for the last stage, communicating, the teachers need to assess the students while they present the result of their work and give reinforcement to the students and should play their roles at least as assessor and prompter or motivator. Furthermore, here are two general stages of learning that also set on the Regulation of the Ministry of Education and Culture of the Republic of Indonesia No. 81a (2013), opening and closing. In the opening activity, the teachers are asked to play their roles at least as prompter and controller. While in the closing stage, the teachers are suggested to play their roles as the organizer, controller, and facilitator.

Considering this fact, however, in reality, it seemed that many teachers still do not understand about the change of teachers' roles as recommended by Curriculum 2013. Is it true? It would be interesting to find out the truth by conducting further research related to this.Based on preliminary observation that had ever been conducted at one of junior high schools at Singaraja, SMP Negeri 1 Singaraja, it seemed that one of the teachers had been implementing appropriate roles accordingto Scientific Approach. For instance, he facilitated the students enrichment activity by asking them to do 
the assignment or exercises in group work about Narrative Text, he played their roles in the process of teaching as part of organizer, prompter, facilitator, and also as the controller.

Since it was done by one teacher, it should be questioned, "What about the other teachers and other classes? Do they do the same or not?". Capturing this reality, it was interesting to observe the teachers' roles played at SMP Negeri 1 Singaraja. It was very important to know from other teachers and classes so that more detail study should be conducted to answer the research questions "What roles do the teachers play in the classrooms when teaching English at SMP Negeri 1 Singaraja?" and "What are responses of students toward the roles that the teachers play in teaching English based on Curriculum 2013 at SMP Negeri 1 Singaraja?"

To conduct the study related to the roles played by the teachers and the responses of the students toward it, it used some previous related studies as references. Out of 7 previous related studies used as references for this current study, a study was conducted by Malik, Murtaza, and Khan (2011) on "Role of Teachers in Managing Teaching Learning Situation" is one of the studies that is similar with this current study. It found out the actual roles played by the teachers in teaching learning situation and also found out the responses of the students toward it. What makes it different with the current study is because the study conducted by Malik, Murtaza, and Khan (2011) focused on assessing Science teachers while this study focused on how the English teachers play their roles in the teaching and learning process.

\section{METHODS}

This study followed qualitative interactive descriptive model, approach, and design which was adopting the framework of Maxwell (2012). The data of this study collected through observation and questionnaire distribution. For the observation, it was considered as the main method used to collect the data about the roles which played by the teachers in the process of teaching English at SMP Negeri 1 Singaraja. To conduct the observation, it used three instruments such as the researcher as the main character since she was the main instrument, the audio recorder which used to record the utterances both of the teachers and the students, and the video recorder which used to record the interaction between the teachers and the students during the teaching and learning process.

Then for the questionnaire distribution, this conducted to know about the responses of the students toward the implementation of teachers' roles in teaching English at SMP Negeri 1 Singaraja. It obviously used the questionnaire as the instrument to collect the data. The questionnaire was developed based on 5 Likert Scale.

The data collected were later analyzed descriptively by adopting the framework from Miles and Huberman (1994). Furthermore, to make sure the validity of the data, there were two steps to be followed in this study, instrument validity and trustworthiness. Instrument Validity done by using the expert judgments. Based on the judgments done by two experts toward the instrument for this study related to the second research question, the total score was 67.5 which indicated that the instrument was highly valid. While for the trustworthiness in this study, triangulation by data source was chosen. According to Hales (2010), there are three aspects in triangulation by data source such as; 1) different spaces, 2) different times, and 3) different persons.

For different spaces, there were nine classes used as places to conduct the observation while there were six classes used as places to conduct the questionnaire distribution. For conducting the observation, the classes used Class 7A1, Class 7A4, Class 7A6, Class 7A7, Class 7A9, Class 8A4, Class 8A7, Class 8A8, and Class 8A9 at SMP Negeri 1 Singaraja. While for the questionnaire distribution, it took place at Class 7A1, Class 7A4, Class 7A7, Class 7A9, Class 8A8, and Class 8A9 at SMP Negeri 1 Singaraja.

For different times, it refers to different times spent for collecting the data needed. In this study, the observation and questionnaire distribution were conducted repeatedly until the data saturated at SMP Negeri 1 Singaraja. While different persons refer to persons chosen as the subjects of the study. This study collected the data from three teachers who taught different classes at SMP Negeri 1 Singaraja.

\section{RESULT AND DISCUSSION}

This chapter presents the findings of the data, the discussions, and the implication. The findings show the result of this study which had been analyzed descriptively, the discussions of this 
study present the elaboration of the result based on the theories, and the implication presents the conclusion which is not explicitly stated.

Research question 1 is about the roles of the teachers are played in the classroom when teaching English at SMP Negeri 1 Singaraja. The following chart will present the data of the roles of three teachers based on the verbal language used.

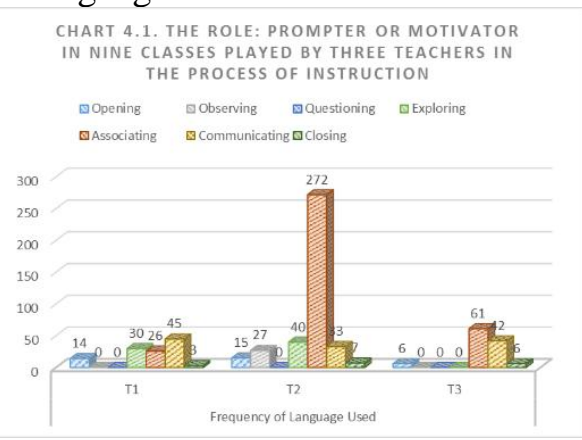

Chart 1. The Role: Prompter or Motivator in Nine Classes Played by Three Teachers in the Process of Instruction

Based on the Chart 4.1. The Role: Prompter or Motivator in nine classes played by three teachers in the process of instruction, the frequency of the teachers' role as Prompter or Motivator indicated by the language used occurred in the Settings of Scientific Approach during English Language Classroom instruction. It showed that Associating had the highest frequency of Prompter or Motivator (359) followed by Communicating (120). Then, the next lower frequency of Prompter or Motivator was in the Setting of Exploring (70). Moreover, it was followed by the Setting of Opening (35), the Setting of Observing (27), and the Setting of Closing (16). Meanwhile, there was no the same role played by the teacher in the Setting of Questioning.

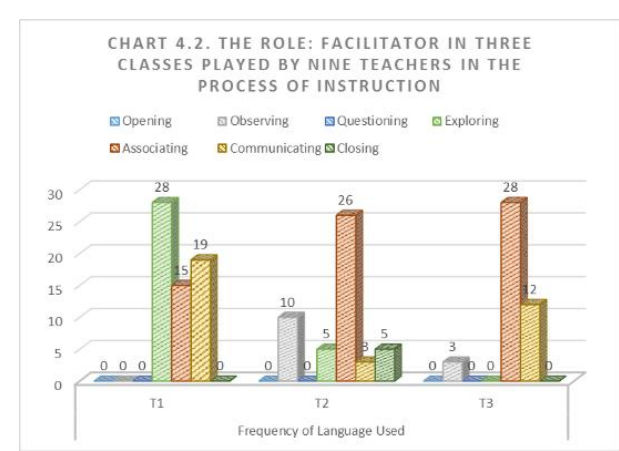

Chart 2. The Role: Facilitator in Nine Classes Played by Three Teachers in the Process of Instruction

Based on the Chart 4.2. The Role: Facilitator in nine classes played by three teachers in the process of instruction, it can be found that the frequency of the teachers' role as Facilitator indicated by the language used happened in the Settings of Scientific Approach during English Language Classroom instruction. It presented that Associating had the highest frequency of Facilitator (69) followed by Communicating (34). While the next lower frequency of Facilitator was in the Setting of Exploring (33), followed by the Setting of Observing (13), and the Setting of Closing (5). As it was indicated on the table, there was no the same role played by the teachers in the Settings of Opening and Questioning. 


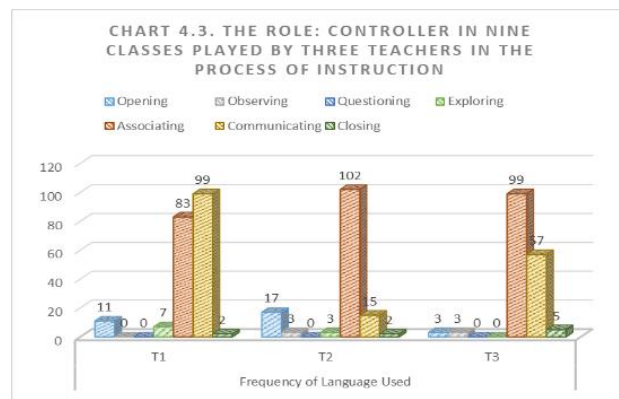

Chart 3. The Role: Controller in Nine Classes Played by Three Teachers in the Process of Instruction

As presented on the Chart 4.3. The Role: Controller in nine classes played by three teachers in the process of instruction, the frequency of the teachers' role as Controller indicated by the language used occurred in the Settings of Scientific Approach during English Language Classroom instruction. Associating had the highest frequency of Controller (284) which was followed by Communicating (171). Then, the next lower frequency of Controller was in the Setting of Opening (31). In addition, it was followed by the Setting of Exploring (10), the Setting of Closing (8), and the Setting of Observing (6). However, there was no the same role played by the teacher in the Setting of Questioning.

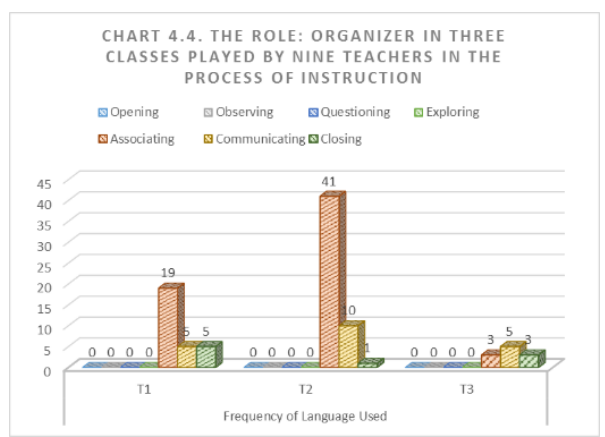

Chart 4. The Role: Organizer in Nine Classes Played by Three Teachers in the Process of Instruction

As shown on the Chart 4.4. The Role: Organizer in nine classes played by three teachers in the process of instruction, the frequency of the teachers' role as Organizer indicated by the language used happened in the Settings of Scientific Approach during English Language Classroom instruction. The highest frequency of teacher as Organizer can be found in the setting of Associating (63) which was followed by Communicating (20), and Closing (9). From the table presented, there was no the same role played by the teacher found in the Settings of Opening, Observing, Questioning, and Exploring.

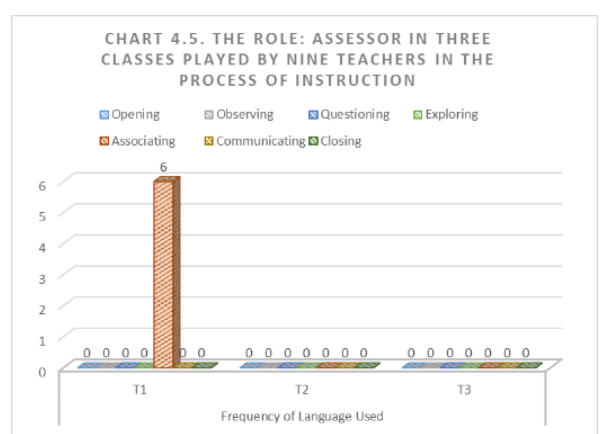

Chart 5. The Role: Assessor in Nine Classes Played by Three Teachers in the Process of Instruction

From the Chart 5. The Role: Assessor in nine classes played by three teachers in the process of instruction, it can be found that the frequency of the teacher' role as Assessor indicated by the language used occurred in the Setting of Scientific Approach during English Language Classroom 
instruction. The role of the teacher as the assessor was happened only in the setting of Associating 6 times which was played by the teacher 1 . There was no the same role played by the teacher 2 and 3 in other Settings of Scientific Approach.

As had been explained above, there are 8 roles of teacher that can be played in EFL Classroom Instruction according to Harmer (2007) such as prompter or motivator, facilitator, organizer, controller, assessor, participant, tutor, and resource. English teachers at SMP Negeri 1 Singarajahad implemented Curriculum 2013 which meant the processes of instruction were following the Scientific Approach, the teachers adopted student-centered learning in the EFL Classroom. One important principle implemented in the learning process was about the center of learning activities where the role of the students shifted from being informed into getting themselves information. The students were required to be more active in the classroom while the teacher was required to facilitate their learning process.

The Finding indicated that most of the roles played by the teachers in the classrooms involved teacher as prompter or motivator, as facilitator, teacher as controller, teacher as organizer, and teacher as assessor. They appeared in every setting where Scientific Approach was implemented, except in the setting of Questioning. It meant that the process of language learning had already been dominated by student active learning process. The teacher role as resource did not appear because most of the classroom activities consisted of completing the task and doing exercises.

From the data presented above, five roles of the teachers played in various settings of instruction (see on the chart 4.1 until 4.5), except in the Setting of Questioning. It did not appear because the classroom learning activities focused on asking the students to do the assignment or exercises in group work or pair work. Therefore, there were no questioning stage intentionally set in the learning process. However, the students were given time to ask questions while working on their assignment and exercises. So that, questioning appeared as part of other stages like Exploring, Associating, and Communicating. For instance, one student asked his teacher in the setting of Associating, "What is trunk, Mr.?" Then the teacher replied, "Trunk? What is trunk? Trunk is a long part of animal to eat the food." This evidenced that the setting of questioning could take place in other settings.

It was indicated on the Finding that variety of the teachers' roles appeared in the classroom instructional activities which reflected that the activities of learning were dominated by the students. It meant that the approach and method implemented based on Curriculum 2013 had been successfully carried out.

Through this, it can be concluded that there were five roles the teachers played in the classroom when teaching English at SMP Negeri 1 Singaraja such as prompter or motivator in the settings of Opening, Observing, Exploring, Associating, Communicating, and Closing, facilitator in the settings of Observing, Exploring, Associating, and Communicating, and Closing, controller in the settings of Opening, Observing, Exploring, Associating, Communicating, and Closing, organizer in the setting of Associating, Communicating, and Closing, and assessor in the setting of Associating.

On the other hand,the finding related to the research question 2 indicated that the students confirmed that they felt helped when the teachers often decided and managed them to work in group, individually, or classically to finish some work. While in the reality, number of the students argued that their teachers often decided and managed them to work in group, individually, or classically to finish some work. This meant that the expectation of the students and the reality that happened in the EFL Classroom Instructions were in line. In addition, the process of learning activities in the classroom was dominated by group works or individual works in doing exercises or completing the task where the teachers were involved as organizer. This also indicated that the process had the students as the center of learning.

The other role of the teachers was also very prominent like teacher as prompter. It was proved by group of students were helped in the process of learning because the teachers provided clues to answer questions in the learning process. The fact indicated that the teachers had successfully answered students' expectation because number of the students agreed that their teachers often gave them clues when they answered questions. When the teachers became prompter, some of the students said that they felt helped when the teachers gave them compliment and motivation to answer the questions given while the fact showed that the teachers sometimes gave them compliment and 
motivation when they had questions to answer. It has proved that the teachers really played their role as prompter in supportive ways.

Furthermore, the students' responses toward the role as facilitator indicated that the teachers often helped the students a lot in the learning process by giving them a clear instruction for the activity they were going to have. It answered students' expectation since numbers of the students felt helped when their teachers helped them a lot in the learning process by giving them a clear instruction for the activity they were going to have.

The data also showed that numbers of the students felt helped when their teachers controlled the class well which was supported by the reality based on students' responses that the teachers often controlled the students in the learning process.

The last role that the teachers played was very important such as assessor. The students stated that they were helped when the teachers gave scores toward students' work and performance in the learning process while the fact said that he teachers often gave scores toward students' work and performance in the learning process. From two statements written, the reality was just the same as what expected by the students.

The findings and discussion presented above were supported by the theory/concepts used in this research since the data collected for the finding of the roles that the teachers played when teaching English at SMP Negeri 1 Singaraja were classified based on Harmer's Theory. This study used Harmer's Theory which tells about the description of roles that may be played by the teachers when teaching in EFL Classroom. Moreover, the finding also supported by other theories, those are Curriculum 2013 and Student-Centered Learning, since the finding indicated that variety of teachers' roles appeared in the classroom instructional activities which reflected that the activities of learning dominated by the students. It meant that the approach and method implemented based on Curriculum 2013 had been successfully carried out while it also indicated that it has applied the student centered learning since the students influence the content, activities, materials, and pace of learning like what Guzman (2016) said. In addition, because there was the implementation of Scientific Approach in the teaching and learning process, the data presented into tables based on the settings of Scientific Approach. Besides, for the finding of the responses of the students toward the roles that the teachers played in teaching English, it was also supported by the theory/ concept used in this research since the instrument developed by considering Harmer's Theory. Then the result of the previous studies also supported the findings of this study since they give views of the natural phenomenon that may be happened also in this current study.

\section{CONCLUSIONS}

Two research questions for this study have been answered and defined based on the research conducted at SMP Negeri 1 Singaraja. Related to the research question 1, "What roles do the teachers play in the classroom when teaching English at SMP Negeri 1 Singaraja?", it can be concluded that there are five roles the teachers play in the classroom when teaching English at SMP Negeri 1 Singaraja such as prompter or motivator, facilitator, controller, organizer, and assessor. And for the research question 2, "What are the responses of the students toward the roles that the teachers play in teaching English based on Curriculum 2013 at SMP Negeri 1 Singaraja?", it can be found that the responses of the students toward the roles that the teacher play in teaching English based on Curriculum 2013 mostly dominated by positive attitude. Their responses are they felt that they accepted great amount of help when the teachers played the roles as prompter or motivator, facilitator, organizer, controller, and assessor.

Based on the findings presented, most of the roles that the teachers played supported the student centered based learning. It is the result of the classroom focused activities developing on giving exercises, completing task, and doing practice of language used. It would pedagogically imply that the other types of classroom focused activities should also be developed by considering relevant teachers' roles in order to support the implementation of Scientific Approach. Improvement of the teachers' instructional strategies was also very important in particular to facilitate the process of language learning. Developing the teacher roles to improve the students' learning motivation should be taken into account. Teachers should improve their roles in the instructional strategies relevant to the use of technology in the process of classroom language learning while reducing the role as 
resources. So, the students will be more creative, active, and innovative. Then, it is also expected that the result of this study can be used as a reference for the other researchers who want to conduct the same study. The researcher also suggests the other researchers to develop the research design and conduct this kind of research in the wider area which has more objects and subjects. Indeed, this needs longer time to be done.

\section{REFERENCES}

Firmansyah, E. 2015. A Study on the Principals' and English Teachers' Perceptions about Curriculum 2013 and Its Implementation. A Thesis. English Education Study Program School of Postgraduate Studies. Indonesia University of Education, Bandung.

Guzman, M. 2016. "Preferred Student-Centered Strategies in Teacher Education: Input to OutcomesBased Instruction". Asia Pacific Journal of Education, Arts and Sciences, 3(1).

Hales, D. 2010. An Introduction of Triangulation. Switzerland: UNAIDS.

Harmer, J. 2007. "The Practice of English Language Teaching: Fourth Edition". China: Pearson Education Limited.Hayes, R. L., \& Lin, H. (1994). Coming to America: Developing social support systems for international students. Journal of Multicultural Counseling and Development, 22, 7-16. doi:10.1002/j.2161-1912.1994.tb00238.x

Malik, M.A., Murtaza, A., and Khan, A.M. 2011. "Role of Teachers in Managing Teaching Learning Situation". Interdisciplinary Journal of Contemporary Research in Business, 3(5).

Maxwell, J. 2012. "Qualitative Research Design: An Interactive Approach". Retrieved from: https://www.researchgate.net/publication/43220402 (accessed on June 20th, 2018).

Miles, M.B. and Huberman, A.M. (1994). Qualitative Data Analysis, 2nd Ed., p. 10-12. Newbury Park, CA: Sage.

Ministry of Education and Culture in Indonesia. 2014. PerubahanPolaPikirdalamKurikulum 2013. Jakarta.

Regulation of Ministry of Education and Culture in Indonesia No. 22 Year 2016 about Standard Process of Primary and Secondary Education, 2016. Jakarta: BSNP Indonesia.

Regulation of the Ministry of Education and Culture in Indonesia No. 81a of 2013 on the Implementation of the General Guidelines Curriculum, 2013. Jakarta: BSNP Indonesia.

Rumahlatua, D., Huliselan, E.K., and Takariaa, J. 2016. "An Analysis of the Readiness and Implementation of 2013 Curriculum in the West Part of Seram District, Maluku Province, Indonesia”. International Journal of Environmental \& Science Education 2016, 11(12).

Thanh, P.T. 2010. "Implementing a Student-Centered Learning Approach at Vietnamese Higher Education Institutions: Barriers under Layers of Casual Layered Analysis (CLA)". Journal of Futures Studies, 15(1), p(21-38).

Zohrabi, M., Torabi, M.A. and Baybourdiani, P. 2012. "Teacher-Centered and/or Student-Centered Learning: English Language in Iran”. English Language and Literature Studies, 2(3). 